\title{
Improving Literacy Instructional Practices in Primary Schools in Nigeria: Strategies that Work
}

\author{
Timothy O. Oyetunde, Gloria Ojo, Katrina A. Korb, Gladys Babudoh \\ University of Jos, Nigeria
}

\begin{abstract}
Poor teaching methods are blamed for a large number of Nigerian pupils in government schools becoming either non-readers or struggling readers [20]. This study investigated the effects of a Reading Intervention that trained primary school teachers in specific strategies of teaching reading skills in order to enhance instructional practices. In a quasiexperimental design with 15 teachers and 140 primary pupils, teachers were trained for four weeks using activities derived from the whole language or literature-based approach. The teachers then trained pupils for eight weeks in reading skills in an afterschool programme. The reading assessment measured pupils' skills in oral language, print awareness, sight word recognition, phonemic awareness, and listening comprehension. Results of post-test showed progress in pupils' ability to express themselves in English; recognize a large number of sight words; generate language experience stories and read simple story books. Another outcome included production of storybooks from children's language experiences stories.
\end{abstract}

\section{Introduction}

One serious problem currently facing primary education in Nigeria is illiteracy. An alarmingly high percentage of primary school children are not learning to read, and a lot more do not know how to read to learn, that is, they cannot use reading as a tool of learning [2], [12], [22], [24], [27], [29]. In specific terms, only about $33 \%$ of Nigerians within the ages 6 14 are literate [17]. Bunza [5] warns that, "there are many children 'at risk' and unless we come to their rescue, the age of darkness might recur" (p. v).

The reasons for the widespread reading failure in schools are many, but four particularly merit attention here. First, teachers are inadequately prepared because teacher-education programmes do not emphasize reading as a skill that is necessary to be taught to preservice teachers.

The second reason, deriving from the first, for massive reading failure is that the nature of the reading process is not generally understood by Nigerian primary school teachers [13], [12], [19], [22], [27]. The fact is that reading is a very complex process that requires the development of many literacy skills, including oral language skills, sight word recognition, decoding skills and comprehension strategies among many others. Recent research has provided substantial evidence about the importance of three aspects of literacy development. First, children begin to learn to read very early in life [26], a concept called emergent literacy. Second, a strong foundation in oral language is a prerequisite to learning to read [25], reading meaningful texts promotes greater interest in learning to read and better literacy achievement [11]. However, teachers in Nigeria often have outdated and inaccurate beliefs of literacy development, mistakenly focusing on intensive drills on isolated reading skills [15]. A solid understanding of literacy development is a prerequisite to using instructional practices that effectively foster early literacy skills and attitudes.

Furthermore, teachers use poor methodology in teaching reading skills, assuming that pupils will "catch" reading skills through the general teaching of English. One of the most important factors that determine how well children learn is the classroom teacher's knowledge and teaching skills [4]. Research and experience have shown that children in a second language situation, such as in Nigeria, can be meaningfully taught to read and read to learn if teachers are properly trained and the appropriate methods and techniques are applied [12], [31]. The best protection against illiteracy is quality instruction from a knowledgeable, effective teacher [26]. Because teachers do not use effective instructional practices for reading and literacy, pupils have poor reading skills and have a poor attitude toward reading.

Finally, the fourth factor militating against effective acquisition of literacy skills in primary schools is the neglect the primary school system has suffered over the years [1], [12]. This neglect is particularly reflected in the paucity of instructional facilities, especially culturally-relevant reading materials for young children. Research has provided overwhelming evidence that reading high quality, meaningful literature with young children promotes 
literacy development [6], [14], [26]. Frequently reading storybooks relates to better literacy skills [7], even for young children in sub-Saharan Africa [9]. Specifically, reading storybooks promotes vocabulary, even for students who are learning to read in their second language [30]. Reading authentic materials with young children also fosters interest in reading [16].

\section{Statement of the problem}

The major problem to be addressed in this study is the low functional literacy among Nigerian children. The more general problem of widespread academic failure of Nigerian students can be rooted back to the problem of poor reading skills. Students who cannot read are unable to learn in a broad range of subjects, including mathematics, science, social studies, and other subjects, because reading is a prerequisite skill for learning in formal education. As previously mentioned, the four primary factors causing the problem of low functional literacy are inadequate preparation for teaching reading skills in teachereducation programmes, the nature of the reading process is not understood by teachers, teachers use poor instructional practices in teaching reading skills, and neglect of the primary school system that is reflected in the paucity of culturally-relevant reading materials.

\section{Purpose of study}

This project was designed to train public primary teachers in effective strategies for teaching beginning reading skills and concepts using the whole language approach to improve reading skills amongst primary one pupils. The specific objectives of this study focused on the student outcomes, as follows.

- Determine the effect of the whole language approach on oral language of primary one pupils in Jos Metropolis government schools.

- Determine the effect of the whole language approach on print awareness of primary one pupils in Jos Metropolis government schools.

- Determine the effect of the whole language approach on phonemic awareness of primary one pupils in Jos Metropolis government schools.

- Determine the effect of the whole language approach on primary one pupils' reading fluency in Jos Metropolis government schools.

- Determine the effect of the whole language approach on the listening comprehension skills in Jos Metropolis government schools.

\section{Research hypotheses}

The research hypotheses that guided the study were as follows.

- There is no significant effect of the whole language approach on the oral language of primary one pupils in Jos Metropolis government schools.

- There is no significant effect of the whole language approach on print awareness of primary one pupils in Jos Metropolis government schools.

- There is no significant effect of the whole language approach on phonemic awareness of primary one pupils in Jos Metropolis government schools.

- There is no significant effect of the whole language approach on reading fluency of primary one pupils in Jos Metropolis government schools.

- There is no significant effect of the whole language approach on listening comprehension of primary one pupils in Jos Metropolis government schools.

\section{Method and Procedure}

\subsection{Research design}

This study used a pre- and post-test quasiexperimental research design. Children from each of the five primary schools were assigned to the Treatment and Control groups. All children were pretested on their reading skills. Children in the Treatment group then received eight weeks of the Enhancing Reading Intervention whereas children in the control group received no intervention. After the eight weeks of intervention, all children were again post-tested on their reading skills using the same assessment. The treatment group had a total of 76 pupils and the control group had a total of 64 pupils.

\subsection{Population}

The target population for this study included children in primary one at government schools in Jos Metropolis. Four government schools in Jos were selected at random given the fact that the government schools in Jos have basically the same characteristics. In each school, forty children were selected and classes were kept intact. A total of 140 pupils in primary one completed both the pre- and post-test so were included as the sample for the study. Fifteen teachers were also selected from the 5 schools. They were the class teachers of primary one or two and were recommended by their supervisors on the basis of their commitment. 
As seen in Table 1, there were slightly more female pupils in both the treatment and control groups. There was no significant relationship between gender and the group that the children were assigned to $\left(\chi^{2}(4\right.$, $\mathrm{N}=140)=1.30, \mathrm{p}=.25)$. The average age of the treatment group was 7.36 years $(\mathrm{SD}=1.46)$ and the average age of the control group was 7.34 years (1.52). There was also no significant difference between the two groups in age $(t(138)=0.05, \mathrm{p}=.96)$.

Table 1. Gender of Participants

\begin{tabular}{lccccc}
\hline & \multicolumn{2}{c}{ Male } & \multicolumn{2}{c}{ Female } & \\
\cline { 2 - 5 } & $\mathrm{N}$ & $\%$ & $\mathrm{~N}$ & $\%$ & Tot \\
\hline Treat. & 37 & 26.43 & 39 & 27.86 & 76 \\
Cont. & 25 & 17.86 & 39 & 27.86 & 64 \\
\hline Total & 62 & 44.29 & 78 & 55.71 & 140 \\
\hline
\end{tabular}

\subsection{Instruments}

A one-on-one reading assessment was developed by the researchers to measure each of the five foundational reading skills. Oral language was measured by one subtest with ten simple questions that children had to answer. Because fluency in any language, not just English, has been found to improve reading skills [10], children were allowed to respond either in English or Hausa. For example, one question was How old are you. Any reasonable answer was marked correct.

Print awareness was measured by three subtests. For the first subtest entitled Print Awareness, the teacher presented a book to the child, and the child was asked ten questions to demonstrate their awareness of print conventions. For example, the child was first asked to point to the title of the book. Another item asked the child to demonstrate knowledge of reading text from left to right. The other two subtests, Knowledge of Upper Case Letters and Knowledge of Lower Case Letters, asked children to correctly identify the 26 letters of the alphabet. Letters were printed on small pieces of cardboard and were randomly shuffled. Children received one point for each letter they correctly identified.

Phonemic awareness was measured by one subtest with ten items that asked children to identify sounds within words. For example, children were asked, "What is the first sound in the word dog?". Children were scored as correct if they identified the correct sound.

Reading fluency was measured by two subtests. In the first subtest, the pupil was given a list of the 100 high frequency words in English [28]. Each child was then given 60 seconds to read as many words as they could. In the second subtest, the pupil was given a reading passage with 118 simple words. They were given three minutes to read as many words as they could. The final score reflected the number of words correctly read in the given timeframe.

Listening comprehension was measured by two subtests with ten items each. For both subtests, children were asked to answer questions based on their understanding of a simple story. In the first subtest, Listening Comprehension During Reading, children were read one or two sentences at a time of a traditional story about a rat who helped a lion. After one or two sentences, the child was asked a question to test their understanding of those few sentences. In the second subtest, Listening Comprehension of a passage, the teacher read half of a story about a city and village mouse who each visited the other in their home. Halfway through the passage, children were asked five questions to assess their understanding of the passage. At the end of the passage, five more questions were asked for a total of ten questions.

\subsection{Procedure for data collection}

The intervention was carried out in two phases. Phase one included teacher training in instructional practices and phase two included pupils' participation in a reading and literacy program that included training in reading skills using variety of strategies.

5.4.1. Teacher training. The first phase involved the 15 teachers being trained for four weeks two hours daily after school in literacy instructional practices. The one major objective guided the training is that this would result in teachers being able to demonstrate an awareness of the nature of reading and literacy, describe the basic skills of reading and literacy, and apply appropriate strategies of teaching specific skills of reading and literacy. The first two weeks of the teacher training were focused on describing the nature of the reading process and demonstration of teaching methods for reading acquisition. In the final two weeks of the teacher training, children from a local primary school were brought in to enable the teachers to implement the instructional practices in practical sessions as the facilitators observed their teaching methods and provided feedback. The teachers were also taught how to administer the reading assessment used for the pre- and post-test.

5.4.2. Pupils training in reading skills. After the four weeks of teacher training, the primary school teachers implemented an eight week after school literacy program for pupils in primary one. Twenty pupils in the treatment group were selected to participate in the program in each school for 2 hours daily four times a week. The objectives of the pupils programme were as follows. The first objective was that pupils would acquire oral language competence as a tool for reading and literacy. The second objective is that pupils would develop print awareness. The third objective is that 
pupils would acquire sight words and decoding skills The final objective is that pupils would be able to read story books.

During the first week of the program, children were pre-tested on the reading assessment. For the next eight subsequent weeks, the children were taught, using specially designed lesson plans which developed their literacy skills in the four basic areas: oral language development, print awareness, sight words, decoding, and listening comprehension. The pupils were steeped in sessions which were aimed at teaching them to express themselves meaningfully in English, to recognize a large store of high frequency words, to generate language experience stories, to identify lettersound relationships and to listen and respond to simple stories being read. The strategies employed were elements of the whole language or literature based approach to reading instruction. This approach integrates language skills and encourages learners to actively participate in the process of learning to read; that is, reading is presented as a personally meaningful means of communication.

In the last week of the program, children were post-tested using the same reading assessment with the same administration procedures.

\section{Results}

The first analysis compared the treatment to the control groups on pre-test data for all nine reading skills sub-tests. The treatment group was significantly higher than the control group on four of the nine reading skills: oral language $(t(138)=1.99, \mathrm{p}=.049)$, print awareness $(t(138)=2.09, \mathrm{p}=.038)$, comprehension in reading $(t(138)=2.21, \mathrm{p}=.029)$, and comprehension after reading $(t(138)=2.31, \mathrm{p}=$ .022). There was no significant difference between the treatment and control group on the remaining pretests: upper case letters $(t(138)=0.1$, ns), lower case letters $(t(138)=0.17, \mathrm{~ns})$, phonemic awareness $(t(138)$ $=1.11$, ns $)$, sight words $(t(138)=1.23$, ns $)$, and passage reading fluency $(t(138)=1.95, \mathrm{~ns})$.

Due to the significant differences between the treatment and control group on half of the pre-tests, each hypothesis was analysed with the Analysis of Covariance (ANCOVA) to compare the treatment and control groups' post-test scores while controlling for the pre-test scores. The adjusted means and standard deviations for each sub-test are presented in Table 2.

As can be seen from Table 3, the treatment group significantly outperformed the control group on all nine reading skills sub-tests. Therefore, all null hypotheses were rejected.
Table 2. Adjusted means and standard deviation of reading skills

\begin{tabular}{|c|c|c|c|c|c|}
\hline & \multirow[b]{2}{*}{$\begin{array}{l}\text { Max. } \\
\text { Score }\end{array}$} & \multicolumn{2}{|c|}{ Treatment } & \multicolumn{2}{|c|}{ Control } \\
\hline & & Mean & SD & Mean & $\mathrm{SD}$ \\
\hline Oral Language & 10 & 9.61 & 0.52 & 8.87 & 0.65 \\
\hline $\begin{array}{l}\text { Print Aware. } \\
\text { Print Aware.: }\end{array}$ & 10 & 8.45 & 2.65 & 5.76 & 3.47 \\
\hline $\begin{array}{l}\text { Lower Case } \\
\text { Print Aware.: }\end{array}$ & 26 & 17.31 & 9.03 & 13.25 & 10.06 \\
\hline $\begin{array}{l}\text { Upper Case } \\
\text { Phonemic }\end{array}$ & 26 & 17.79 & 9.38 & 13.93 & 9.60 \\
\hline Awareness & 10 & 4.62 & 3.82 & 2.94 & 3.05 \\
\hline $\begin{array}{l}\text { Sight Words } \\
\text { Passage }\end{array}$ & 100 & 11.97 & 15.64 & 5.63 & 12.56 \\
\hline Fluency & 118 & 13.30 & 25.78 & 3.48 & 8.67 \\
\hline $\begin{array}{l}\text { Comprehension } \\
\text { in Reading } \\
\text { Comprehension }\end{array}$ & 10 & 4.72 & 3.78 & 3.36 & 3.56 \\
\hline After Reading & 10 & 4.80 & 3.38 & 3.57 & 3.48 \\
\hline
\end{tabular}

Table 3. ANCOVA comparisons between treatment and control groups

\begin{tabular}{|c|c|c|c|c|}
\hline & $\mathrm{F}$ & $\mathrm{df}^{\mathrm{a}}$ & $\mathrm{P}$ & $\eta^{2}$ \\
\hline Oral Language & 9.25 & 137 & $.003 * *$ & .06 \\
\hline Print Aware. & 27.93 & 137 & $<.0001 * * *$ & .17 \\
\hline Print Aware.: & & & & .08 \\
\hline Lower Case & 11.11 & 133 & $.001 * *$ & \\
\hline Print Aware.: & & & & .08 \\
\hline Upper Case & 11.44 & 137 & $.001 * * *$ & \\
\hline Phonemic & & & & .08 \\
\hline Awareness & 11.49 & 137 & $.001 * * *$ & \\
\hline Fluency: Sight & & & & .07 \\
\hline Words & 10.06 & 136 & $.002 * *$ & \\
\hline Fluency: & & & & .08 \\
\hline Passage & 10.81 & 132 & $.001 * *$ & \\
\hline $\begin{array}{l}\text { Comprehension } \\
\text { in Reading }\end{array}$ & 5.57 & 136 & $.020 *$ & .04 \\
\hline After Reading & 4.83 & 135 & $.030 *$ & .03 \\
\hline
\end{tabular}

The Whole Language Approach was effective in improving all reading skills measured by the study: oral language, print awareness, phonemic awareness, reading fluency including sight word recognition and a reading passage, and listening comprehension.

The effect size was also computed to determine the size of effect that the Whole Language Approach had on primary one pupil's reading skills. The eta squared $\left(\eta^{2}\right)$ statistic reported in Table 3 is the measure of effect size used for ANOVA analyses [3]. Eta squared is calculated by dividing the sum of 
squares of the effect by the total sum of squares. Large effect sizes are greater than .35, medium effect sizes are greater than .15 , and small effect sizes are greater than .02 [8]. Therefore, as seen in Table 3, the Whole Language Approach had a medium effect size on print awareness, and a small effect size on all other reading skills.

\section{Discussion}

The purpose of this study was to train public primary teachers in effective strategies for teaching beginning reading skills and concepts using the whole language approach to improve reading skills amongst primary one pupils. This study focused on the outcome of pupils' reading skills. After only eight weeks of intervention, the Whole Language Approach resulted in improvement in all five reading skills measured by the study. In this section the reason for the success of the project are highlighted.

First, teacher empowerment. This project started with an intensive teacher training in literacy instructional practices. At the end of the training the teachers knew what to do and how to do it.

Second, priority was given to oral language. Oral language skills are critical to learning to read and write. This section is particularly necessary in the Nigerian situation where the out of school environment does not support literacy in English. It is necessary to explain the nature of the performance of the pupils in the oral language sub-test. It can be observed that the pupils displayed a level of oral competence. This came to the researchers as a surprise but because of the nature of the test even if the responses were given in the mother tongue the children were scored to build their confidence.

Third, the intensity of the exposure. This project engaged the pupils in literacy activities four times weekly for two hours a day. This level of exposure needs to be recognized because there must be sufficient time to practice learning to read. Thus, children must be constantly engaged in meaningful literacy tasks [20].

Fourth, emphasis on meaningful integration of language skills. The different skills which were taught in the intervention were done in an integrated manner and were combined towards a holistic approach that kept and sustained the pupils' interest in learning to read.

\section{Recommendations}

In the light of the study, the following recommendations were made

1. Improve teacher training. Provide meaningful reading and literacy instructional activities.
2. Priority attention to be given to literacy. Reading should occupy a place of pride in the curriculum. Reading should be treated as a subject.

3. In order to ensure adequate instructions, emphasis/ attention should be given to create a conducive print-rich school environment. Storybooks, and other basic materials such as cardboards, markers, and writing books for example should be freely used.

4. Teachers should receive adequate incentives for the work they do.

\section{Conclusion}

The result of this study confirms earlier studies and opinions of authorities in terms of the fact that if children are exposed to meaningful literacy activities in a consistent way they will learn to read regardless of whether it is a first language or second language situation. These findings are particularly significant and reassuring in the Nigerian situation where learning to read is problematic for many children. The findings implicate the teacher factor in terms of knowledge of what to do and how to do it.

\section{References}

[1] Akpa, G. O., \& Abama, E. A., (2000). Educational supervision and the success of Universal Basic Education in Nigeria. Journal of Educational Studies, 6, 29-37.

[2] Aliyu, J. S., \& Daudu, H. M., (2011). Writing as feedback of reader's reactions: Are they means for inculcating literacy habits in individuals? A study of the Nigerian situation. Literacy and Reading in Nigeria, 13, 6071.

[3] Bakeman, R., (2006). VII. The practical importance of findings. Monographs of the Society for Research in Child Development, 71, 127-145.

[4] Bowman, B. T., Donovan, M. S., \& Burns, M. S., (2000). Eager to learn: Educating our preschoolers. Washington, DC: National Academies Press.

[5] Bunza, M. M. (1997, September). Strategies for achieving quality of education in assessment in distance education: The NTI Experience. Paper presented at the $15^{\text {th }}$ Annual Conference of the Association for Educational Assessment in Africa.

[6] Bus, A. G., van Ijzendoorn, M. H., \& Pellegrini, A. D., (1995). Joint book reading makes for success in learning to read: A meta-analysis on intergenerational transmission of literacy. Review of Educational research, 65, 1-21.

[7] Campbell, J. R., Donahue, P. L., Reese, C. M., \& Phillips, G. W., (1996). NAEP 1994 reading report card for the nation and the states: Findings from the National Assessment of Educational Progress and trial state 
assessment. Washington, DC: Office of Educational Research and Improvement, US Department of Education.

[8] Cohen, J., (1992). A power primer. Psychological Bulletin, 112, 155-159.

[9] Commeyras, M. \& Inyega, H. N., (2007). An integrative review of teaching reading in Kenyan primary schools. Reading Research Quarterly, 42, 258-281.

[10] Edele, A., \& Stanat, P., (2016). The role of firstlanguage listening comprehension in second-language reading comprehension. Journal of Educational Psychology, 108, 163-180

[11] Fisher, D., Flood, J., \& Lapp, D., (2003). Material matters: Using children's literature to charm readers (or why Harry Potter and the Princess Diaries matter). In L. M. Morrow, L. B. Gambrell, \& M. Pressley (Eds.), Best practices in literacy instruction (2nd ed., pp. 167-186). New York: The Guilford Press.

[12] Gani, A. M., (1991). Support paper: Primary educationfunding. In R. O. Ohuche (Ed.), Moving education in Nigeria toward the year 2000 (pp. 95-96). Lagos: Nigerian Academy of Education.

[13] Hughes, J. O., \& Sanni, K., (1997). The reading lesson An emancipating or a domesticating experience? In B. Lawal, F. A. Obi-Okoye, O. B. Jegede, \& C. E. Onukaogu (Eds.), Literacy and reading in Nigeria, Vol. 7 (pp. 123130). Ile Ife: Reading Association of Nigeria.

[14] International Reading Association \& National Association for the Education of Young Children, (1998). Learning to read and write: Developmentally appropriate practices for young children. Young Children, 53, 30-46.

[15] Korb, K. A., (2010, July). Reading is not a laughing matter: Nigerian teachers' beliefs about literacy development. Poster presented at the 21st International Congress of the International Society for the Study of Behavioral Development, Lusaka, Zambia.

[16] Morrow, L. M. \& Asbury, E., (2003). Current practices in early literacy development. In L. M. Morrow, L. B. Gambrell, \& M. Pressley (Eds.), Best practices in literacy instruction (2nd ed., pp. 43-63). New York: The Guilford Press.

[17] Murtala, A. Y., Babangida, L., Usman, A. I., \& Auwalu, H., (2013). Comparative study of the state of literacy in Nigeria and Cuba. European Scientific Journal, 9, $34-44$.

[18] Omojuwa, J., (1991). Developing reading in mothertongue and English in Nigerian primary schools: Crisis in practice. In T. O. Oyetunde, J. Aliyu, \& Y. Aboderin (Eds.), Literacy and reading in Nigeria, Vol. 5 (pp. 407-416) Lagos: The Nigerian Educational Research and Development Council \& Reading Association of Nigeria.
[19] Oyetunde, T. O., (1997). Helping children become good readers: A guide for parents and teachers. Jos: Reading Association of Nigeria.

[20] Oyetunde, T. O., (2002). Second language reading: Insights from Nigerian primary schools. The Reading Teacher, 55, 748-755.

[21] Oyetunde, T. O., (2009). Beginning reading scheme: Empowering teachers to help their pupils become good readers. Jos: LECAPS Publishers.

[22] Oyetunde, T. O., (2015). Olu, Musa, and Eze cannot read: Arresting the drift toward basic and higher illiteracy. University of Jos Inaugural Lecture Series, 69.

[23] Oyetunde, T. O., Ojo, G., Korb, K. A., \& Babudoh, G., (2016, June). An analysis of public primary one pupils' performance in basic reading skills. Paper presented at the International Conference on Nigerian Child, Jos, Nigeria.

[24] Oyetunde, T. O., \& Umolu, J. J. (1991). Primary education on the brink of collapse: Olu, Eze, and Musa can't read. In S. U. Udoh, G. O. Akpa, \& K. P. Gang (Eds.), Towards a functional primary education for Nigeria (pp. 231-239). Jos: Nigeria Association of Educational Administrators and Planners.

[25] Roskos, K. A., Tabors, P. O., \& Lenhart, L. A., (2009). Oral language and early literacy in preschool: Talking, reading, and writing ( $2^{\text {nd }}$ ed.). Newark, DE: International Reading Association.

[26] Snow, C. E., Burns, M. S., \& Griffin, P., (1998). Preventing reading difficulties in young children. Washington, DC: National Academy Press.

[27] Umolu, J. J. (1997). Reading and reading instruction at the primary and secondary levels: State of the art and strategies for improvement. In T. O. Oyetunde, J. S. Aliyu, A. Nwoke, \& A. F. Miri (Eds.), English teaching improvement (pp. 1-13). Jos: LECAPS Publishers.

[28] Umolu, J. J., \& Mallam, W., (1985). Use of an informal reading inventory for reading assignment of primary school children in Nigeria. Journal of $U$. $K$. Reading, 19, 173-176.

[29] Unoh, S. O. (1983). Reading improvement in Nigeria as a multilingual nation: Problems and prospects. In S. O. Unoh, R. A. Omojuwa, \& S. K. M. Crow (Eds.), Literacy and reading in Nigeria, Vol. 1. Zaria: Institute of Education, Ahmadu Bello University.

[30] Verhallen, M. J. A. J. \& Bus, A. G., (2010). Lowincome immigrant pupils learning vocabulary thru digital picture storybooks, Journal of Educational Psychology, 102(1), 54-61.

[31] Walker, R., Rattanavich, S., \& Oller, J. W., (Eds.) (1992). Teaching all the children to read. Buckingham, England: Open University Press. 